\title{
CBPR Pilot Intervention: Understanding Social Health Determinants of Mental Health in Rural Latinos
}

\author{
Ashley M. Bunting' ${ }^{1}$ RN, BSN \& Jeanne-Marie R. Stacciarini², RN, PhD, \\ FAAN \\ ${ }^{1}$ College of Nursing, University of Florida \\ ${ }^{2}$ Department of Family, Community, and Health System Science, University of Florida
}

Faculty mentor: Jeanne-Marie R. Stacciarini, Department of Family, Community, and Health System Science

\begin{abstract}
The purpose of this study is to identify challenges and facilitators for interventions on determinants of mental health in the literature and to analyze psychosocial determinants of mental health and coping strategies described by rural Latinos during a church-based pilot intervention. This study was a review of literature and secondary data analysis of a larger Community-Based Participatory Research (CBPR) study on the mental well-being of rural Latinos in North Florida - a CBPR pilot intervention. It was developed to identify and respond to social stressors by creating a space where rural Latinos can help one another by sharing their experiences; empowering people to address health determinants that affect their well-being. All data from the pilot intervention was thematically analyzed using NVivo. Psychosocial determinants of mental health described by the participants in the CBPR intervention were: social environment factors (discrimination, family conflict, social isolation, undocumented status) and health services (uninsured \& poor health literacy). Positive coping strategies described by rural Latinos were: avoiding conflictive relationships, alternative medicine, exercise, family \& peer support, health education, community social support, instillation of hope, learn English, spirituality and religiosity. Negative coping strategies described were: categorical thinking, isolation, substance abuse. health

Keywords: Community-based participatory research, rural Latinos, psychosocial determinants, mental
\end{abstract}

\section{Introduction}

The United States has seen an exponential growth and diversification in Hispanic populations, with increasing immigration to new, rural destinations generating a greater need for mental health services (Lichter, 2012). Latinos experience severely inadequate healthcare services resulting from limited financial resources, lack of insurance, and limited cultural/bilingual services (Brennan, Baker, \& Metzler, 2008). Latino immigration outside of existing cultural hubs and into new, rural destinations introduce health determinants with reduced social support systems and resources. Geographic isolation, lack of transportation, and the shortage of health care providers present significant access barriers in rural areas (Cristancho, Peters, \& Garces, 
2016). Rural Latinos are a vastly understudied population, providing few culturally appropriate community interventions to address this major public health issue.

Psychosocial health determinants are defined by Healthy People 2020 as: personal, social, economic, and environmental factors influencing health status. Social inequalities, inadequate health services, geographic immobility, immigration status, and lack of community involvement are established themes of psychosocial health determinants that negatively impact the wellbeing of rural Latinos. Collectively, these systemic inequalities equate to social isolation among rural Latinos. Research suggests the link between social isolation and emotional distress as risk factors in the development of and/or exacerbation of mental health conditions (Hiott, Grzywacz, Davis, Quandt, \& Arcury, 2008, Stacciarini et al., 2014).

Limited access to community mental health interventions and resources exacerbate poor mental wellbeing in rural areas and lead to poorer outcomes in these populations. Studies show that there are more people living below the poverty level in rural areas compared to urban areas (Baernholdt, Yan, Hinton, Rose, \& Mattos, 2012). Additionally, rates of depression are found to be higher in rural areas, while social functioning is significantly lower than in urban settings (Baernholdt et al., 2012). Latino adults are less likely than non-Latino Whites to access mental health care. When health care is accessible, it is more likely to be of lower quality (Institute of Medicine [IOM], 2003; United States Department of Health and Human Services [USDHHS], 2001). The specific aims of this project were to: (1) describe the evidence on challenges and facilitators identified in community interventions related to psychosocial determinants of mental health; (2) analyze psychosocial determinants of mental health and coping strategies described by rural Latinos during a church-based pilot intervention.

\section{Conceptual Framework}

The content of field notes were analyzed based on a conceptual framework identified in the literature: Healthy People 2020 and Commission on Social Determinants of Health (CSDH, 2008). Determinants of mental health are psychosocial health factors such as personal, social, economic, and environmental factors influencing mental health status of an individual. Healthrelated behaviors can be influenced by individuals and are considered as intermediary determinants of health (CSDH, 2008). 


\section{Methods}

This is a secondary data analysis study of a larger Community-Based Participatory Research (CBPR) study on the mental well-being of rural Latinos in North Florida (Stacciarini et al., 2016; Stacciarini et al., 2014). To answer the first aim, a review of the existing literature on interventions of psychosocial determinants of mental health in rural Latinos was performed. The literature review used PubMed to identify relevant primary studies on psychosocial determinants of mental health using keywords: mental health, community-based participatory research or community health, social determinants of health, minority groups or vulnerable populations. Exclusionary criteria included: non-Latino, non-ethnic minority, or non-low socioeconomic status, pediatric interventions, non-mental health focused, incomplete studies, studies older than 10 years, not in English, non-intervention focused or secondary analyses.

The literature was organized and appraised by using NVivo 11. Sources were uploaded as PDF files directly to NVivo 11 and coded using nodes to organize the articles by systematic coding of the following: 1) publication data, 2) purpose of each study, methods utilized in the study, intervention implementation (including type of intervention), and intervention outcomes (challenges, facilitators, limitations). Using node data from NVivo 11, the author was able to identify the relevance and frequency of data based on the number of times information was coded. Special attention was given to intervention outcomes in the literature. Features addressing psychosocial determinants of health and mental health during implementation of the intervention were coded as positive outcomes; challenges of interventions' success were coded as negative outcomes. Additionally, mechanisms to overcome psychosocial determinants of mental health and specified implementation challenges were coded as facilitators.

The second aim analyzed data of a pilot church-based CBPR intervention designed to address determinants of mental health in rural Latinos, which was IRB approved by the University of Florida.

The overall goal of the CBPR intervention was to identify individuals' social stressors and respond to these stressors. This was accomplished by creating a group/space where rural Latinos could help one another by sharing their experiences; empowering people to address health determinants that affect their mental well-being. The intervention was delivered by the principal investigator - a mental health nurse; the main themes discussed during the meetings were recorded using systematic field notes, taken right after all meetings $(n=8)$. The field notes were 
then thematically analyzed (Ryan \& Bernard, 2003) by the author using a conceptual framework of psychosocial determinants of mental health identified in the literature. Data was organized into two parts: a) themes of psychosocial determinants of mental health, described by rural Latinos and b) coping strategies utilized by rural Latinos. All content was analyzed using NVivo 11.

\section{Results}

\section{Review of Literature}

The initial review of literature (ROL) search yielded 405 sources, subsequently analyzed for exclusionary criteria. Urban populations and clinic interventions were included in the literature analysis due to limited sources meeting the original search: rural and community interventions. An additional manual search yielded secondary analyses $(n=5)$, used to identify primary sources $(n=6)$ included in the ROL. The total number of sources from the initial and manual search was 21 , but 7 studies were eliminated based on existing exclusionary criteria to produce a final total of 14 studies for the ROL, as noted in Figure 1.

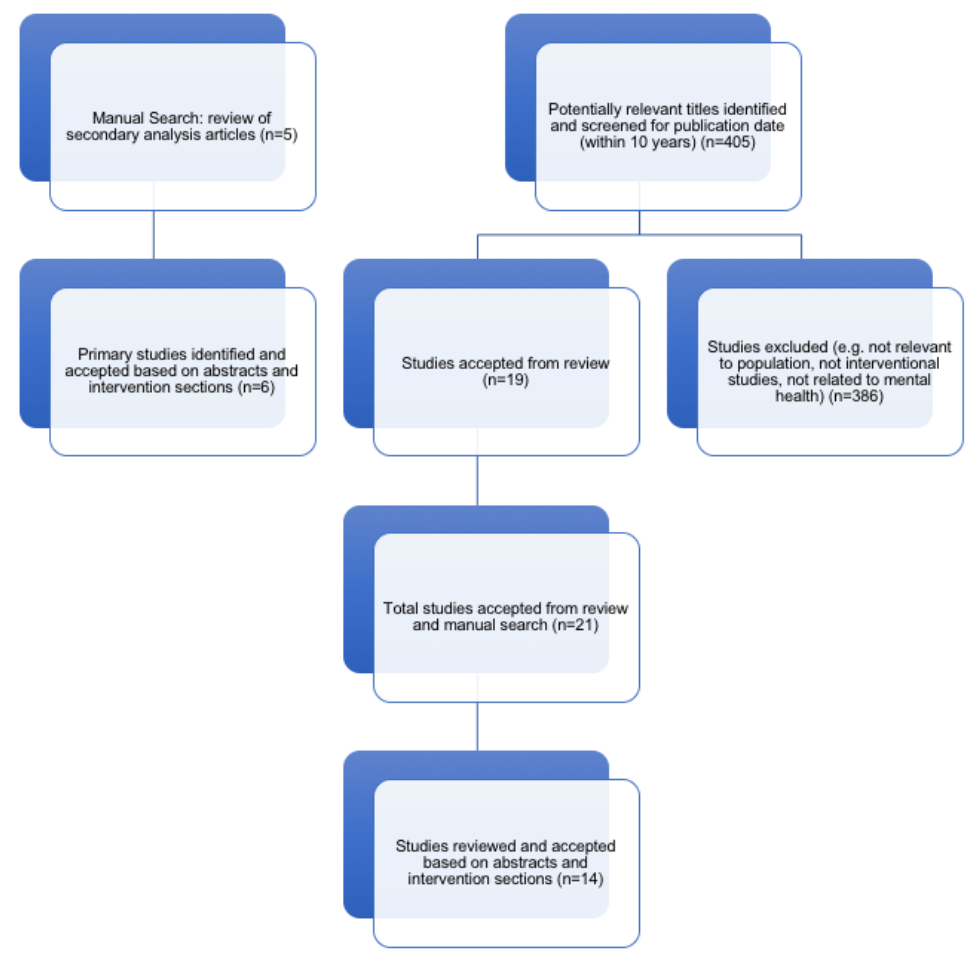

Figure 1. Literature Review Source Collection 
Settings. The interventions were categorized by the setting of implementation, rural or urban, and by the type of intervention, clinic, mixed-methods, or community. Clinic interventions were implemented in outpatient, primary care, or acute care facilities. Community interventions were implemented in non-medical settings, such as churches and community centers. Mixed methods interventions were defined as interventions that combined clinic and community-based settings. Urban interventions comprised the majority of studies identified in the literature $(n=12)$, few were conducted in rural populations $(n=2)$. The urban interventions were: community $(n=5)$, clinic $(n=4)$, mixed methods $(n=3)$. The rural interventions were all clinic interventions $(n=2)$, no community and mixed methods interventions were identified in rural areas. See Table1; Figure 2.

Table 1; Figure 2 Intervention Setting Identified in the Literature

\begin{tabular}{lcc}
\hline Setting & $\begin{array}{c}\text { Urban } \\
(\mathrm{n}=)\end{array}$ & $\begin{array}{c}\text { Rural } \\
(\mathrm{n}=)\end{array}$ \\
\hline Community & 5 & 0 \\
Clinic & 4 & 2 \\
Mixed & 3 & 0 \\
\hline Total & 12 & 2
\end{tabular}

Community intervention-challenges. The literature described access to treatment, time limitations, basic needs unmet, cultural barriers, resistance to medication, cost of service, language barrier and limited transportation. Access to treatment includes financial and insurance barriers to receive mental health services in low socioeconomic status populations (Kaltman, Pauk, \& Alter, 2011; Ryan et al., 2014). Across all settings, patient attendance was limited due to employment and financial inability to take time out of the day to seek treatment (Chong \& Moreno, 2012; Dwight-Johnson et al., 2011). Parenting responsibilities posed a challenge for scheduling and attendance (Kelly \& Pich, 2014). There is a need to meet basic physiological needs - air, food, water, shelter, and clothing - in order to address safety, physical and mental health challenges (Kaltman et al., 2011).

Cultural barriers. Challenges highlighted in the literature were: using technology, stigma toward mental health, limited health literacy, lack of cultural adaptations, and misunderstanding of the United States healthcare system (Alegria et al., 2009; Chong \& Moreno, 2012; DwightJohnson et al., 2011). Telepsychiatry, therapy delivered as a phone intervention with a clinical specialist, and integration of online materials introduce challenges for rural Latinos related to cultural appropriateness (Chong \& Moreno, 2012). Stigma was identified in the literature to be a 
barrier to seek and receive mental health services related to cultural and community values (Chong \& Moreno, 2012). Acculturation and health literacy impact patient access to and knowledge of treatment services, as well as willingness to seek help for mental health (Chong \& Moreno, 2012). It is essential to understand cultural needs in order to address other aspects of diversity, such as age, gender, or sexual orientation (Tondora et al., 2010). Language and limited English proficiency in rural Latinos was identified as a challenge in the delivery and effectiveness of interventions (Chong \& Moreno, 2012; Green et al., 2012). Patients reported feeling uncomfortable and misunderstood when care was delivered by providers in a non-native language, such as English or in the absence of bilingual or bicultural mental healthcare providers (Alegria et al., 2008; Dwight-Johnson et al., 2011). See Figure 3.

\begin{tabular}{|c|c|}
\hline Challenges & Facilitators \\
\hline $\begin{array}{ll}\text { - } & \text { Access to Treatment } \\
\text { - } & \text { Time Limitations } \\
\text { - } & \text { Cusic Needs Unmet } \\
\text { - } & \text { Rtigma) Barriers (technology use, } \\
\text { - } & \text { Cost of Services } \\
\text { - } & \text { Language Barrier } \\
\text { Limited Transportation }\end{array}$ & $\begin{array}{ll}\text { - } & \text { Adaptive Schedule } \\
\text { - } & \text { Fommunity Hub } \\
\text { - } & \text { Life Experience Connection } \\
\text { - } & \text { Pcer Mentors } \\
\text { - } & \text { Fampowerment and Self-Determination Support } \\
\text { - } & \text { Subsidized Cost } \\
\text { - } & \text { Transportalispanish Speaking } \\
\end{array}$ \\
\hline
\end{tabular}

Figure 3 Interventions Addressing Psychosocial Determinants of Mental Health Identified in the Literature

Community intervention facilitators. To overcome challenges, the following facilitators were identified in the ROL: adaptive schedules, community hubs, facilitating cultural bonding (among intervention participants), life experience connection (among intervention participants), peer mentors (promotoras), empowerment and self-determination, family support, subsidized cost, and bilingual/Spanish speaking.

Adaptive scheduling for interventions in the literature was described by expanded hours, increased patient-provider communication, and evening hours to account for working individuals (Barrio \& Yamada, 2010; Dwight-Johnson et al., 2011; Green et al., 2012). Free childcare services were documented as a resource to facilitate intervention success and improve retention rates (Kelly \& Pich, 2014). The use of community hubs as intervention sites support the use of public transportation and civic engagement among community members (Chong \& Moreno, 2012; Green et al., 2012; Kanter, Santiago-Rivera, Rush, Bush, \& West, 2010). Churches are 
comfortable and culturally appropriate settings for rural Latino community-based interventions (Michael, Farquhar, Wiggins, \& Green, 2008; Tondora et al., 2010).

Cultural bonding and life experience connection among participants were identified as protective mechanisms and facilitators for positive intervention outcomes (Barrio \& Yamada, 2010; Tondoro et al., 2011). Cultural bonding describes development of trust through cultural commonalities in group discussions, accommodating transfer of knowledge and social support (Barrio \& Yamada, 2010; Michael et al., 2008; Tondora et al, 2011). Life experience connection transcends culture and ethnicity; participants described feeling "understood by others in the group because 'they know what it's like"” (Kelly \& Pich, 2014).

Promotoras act as peer mentors derived from the Latino community they serve. Promotoras were described as well acquainted with community resources and provided experiential knowledge that is culturally appropriate for the population (Green et al., 2012; Tondora et al., 2010). The use of bilingual, Spanish speaking providers to deliver interventions to Latinos supports cultural appropriateness and understanding (Chong \& Moreno, 2012; Dwight-Johnson et al., 2011; Green et al., 2012; Kaltman et al., 2011; Kanter et al., 2010; Ubelacker et al., 2011). Patients evaluated the use of interpreters as group facilitators and described "feeling understood, despite lag time and potential errors in interpretation" and highlighted the importance of feeling "cared about" and "listened to" as significant factors to overcome language barriers (Kelly \& Pich, 2014). Emphasis on empowerment and self-determination for Latinos was documented in the literature to increase patient satisfaction and engagement in care (Alegria et al., 2008). The literature emphasizes that promoting attitudes of empowerment, perseverance, and strength are culturally appropriate and significant in the process of addressing environmental factors impacting mental wellbeing, and may be "less stigmatizing because they locate the problem [of depression] outside rather than inside the individual" (Kanter et al., 2010).

Engaging family members in mental health interventions and education were documented to increase understanding of patient's illness and improve support systems (Barrio \& Yamada, 2010; Kanter et al., 2010). Principles of Latino culture identified in the literature included: respeto (respect for elders), familismo (family involvement), marianismo/machismo (gender roles) (Green et al., 2012). Subsidized, free intervention services address barriers to implementation and retention, facilitating positive outcomes in the literature (Chong \& Moreno, 2012; Dwight-Johnson et al., 2011; Kaltman et al., 2011; Kelly \& Pich, 2014). 


\section{Pilot Study Thematic Analysis}

The thematic analysis was built upon the conceptual framework of social determinants of health by Healthy People 2020 and the CSDH (2008) and additional articles revised for the ROL considering the "social determinants of mental health" and "coping strategies" to promote mental health (Chong \& Moreno, 2012; Dwight-Johnson et al., 2011; Kaltman et al., 2014). In the data analysis of CBPR pilot intervention, the most common themes of psychosocial determinants of mental health, were: a) social environment and b) health services.

Social environment. This theme describes the determinants of mental health influenced by social structures of a community and environmental implications on mental wellbeing. Categories present within this theme were: discrimination, family conflict, social isolation, undocumented status. Intervention participants reported discrimination as a theme in group meetings. Family conflict was identified as conflict of physical or verbal abuse with children or spouses. Social isolation was described as separation from extended family, being in rural areas, and having limited access to transportation. Undocumented status was a theme associated with feelings of fear related to "getting caught".

Health services. This theme describes health disparities and inequalities in rural Latinos and their implications for mental health. The categories identified within this theme were: uninsured, and poor health literacy. Participants reported the theme of being uninsured as a barrier to healthcare access. Poor health literacy was identified as challenge, and participants described not understanding how the [health] system works, feeling that the system is unfair, and difficulties dealing with new health diagnoses.

Positive coping strategies. To address the psychosocial themes reported above, participants described positive coping strategies, appropriate and constructive responses to stress (Sahler \& Carr, 2009). Positive coping strategies identified: avoiding conflictive relationships, alternative medicine, exercise, seek family \& peer support, seek health education, seek community social support, instillation of hope, learn English, spirituality \& religiosity. Avoiding conflictive relationships was coded as a coping strategy in which participants suggested that they change friend's groups or remove themselves from a stressful situation. Alternative medicine was reported as a way to cope with health difficulties by participants. Exercise was recommended as coping by participants in group meetings. Seeking family and peer support was reported as a coping strategy, describing support provided by family and friends on a personal level (talking to 
someone). Seeking health education was suggested as a strategy to overcome healthcare difficulties and limited health knowledge. Participants suggested that health education be provided by professionals or those who understand the healthcare system to advise them. Looking for community social support, such as getting involved in the community or asking for help from community leaders, was reported as a possible coping strategy. Instillation of hope was a suggested by participants as a coping strategy by using empowerment phrases such as, “don't give up", “don’t be afraid”, “be patient”. Learning English was described by participants as a coping strategy to address language barriers. Spirituality and religiosity were suggested as way of managing distress; including praying and having faith. The coping strategies mentioned are representative of cultural values of this Latino community, and offer feasible tools developed by participants for themselves and peers.

Negative coping strategies. Categorical thinking, isolation, substance abuse were mentioned as ways of handling difficult life situations. Categorical thinking is a black vs. white way of thinking. It was identified in a situation where participants recommended to either support a family member's use of alternative medicine, or to reject and convince them to seek Western treatment. Isolation describes participants' suggestion to remove themselves from family members experiencing problems. Substance use was suggested as a coping strategy to numb or avoid feelings associated with stressors (family conflict, discrimination). The above strategies were evaluated as negative actions or decisions that could be potentially harmful to their mental health, rather than protective. See Figure 4.

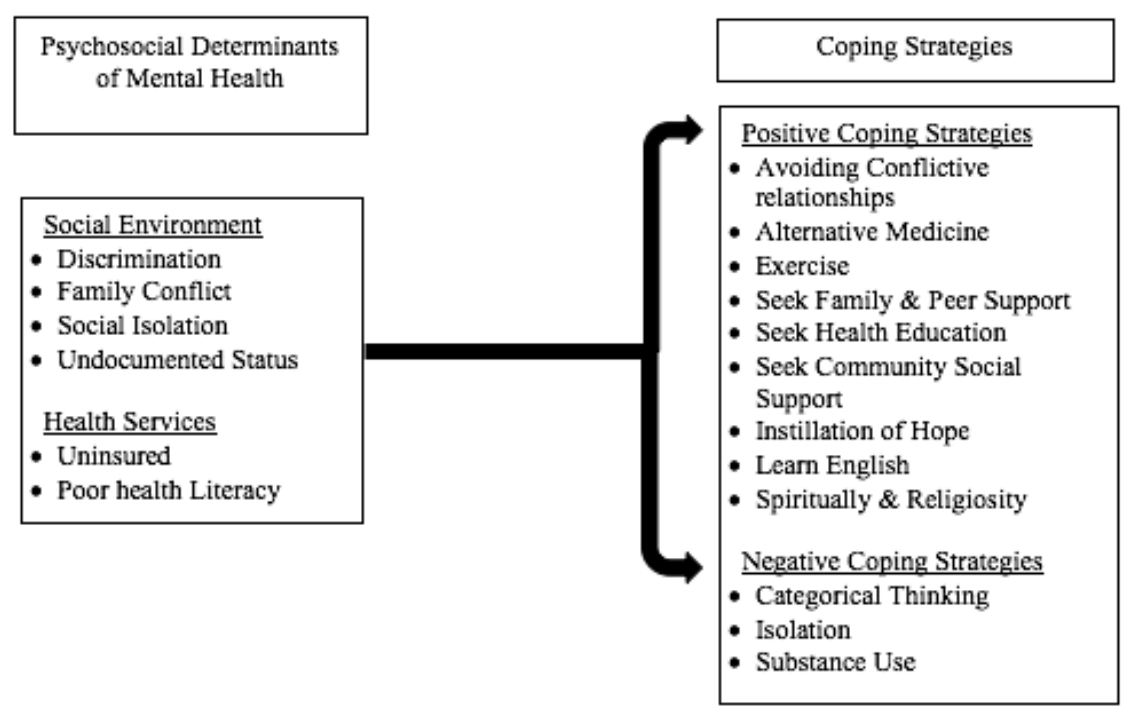

Figure 4. CBPR Church-Based Group Intervention Results 


\section{Discussion}

The aims of this project were to identify the evidence on facilitators and challenges described in interventions of psychosocial determinants of mental health and to analyze psychosocial determinants of a mental health and coping strategies described by rural Latinos during a CBPR church-based pilot intervention.

The psychosocial determinants of mental health described as themes by participants in the CBPR pilot intervention were congruent with the existing literature, including discrimination, social isolation, and lack of health insurance (CDC, 2014; WHO \& CGF, 2014). Facilitators in the literature are reflective of the coping strategies suggested by participants in the CBPR intervention. Cultural and life experience connection, peer support, and family support were identified as facilitators. Family, peer, and community support act as protective mechanisms against social isolation, which is found to exacerbate existing mental health difficulties (Hiott et al., 2008). Addressing language barriers was identified as a positive coping strategy in the pilot intervention and supported by the literature. Promoting positive attitudes of hope and empowerment were reported in the literature review as facilitators and as positive coping mechanisms by rural Latinos.

There were commonalities between intervention facilitators found in the literature and positive coping strategies in the CBPR pilot intervention. This suggest that the strategies of developing support systems (family, community, peers), addressing language barriers, and selfempowerment may be culturally appropriate and relevant to overcome challenges in the rural Latino intervention population (Barrio \& Yamada, 2010; Chong \& Moreno, 2012). Themes discussed in the CBPR group meetings described daily life challenges shared by the participants. Discussion-based interventions facilitate understanding and group problem solving in a culturally appropriate setting (Stacciarini et al., 2014). Group collaboration aids in addressing social isolation and generates peer and community support.

There were several limitations in this study. Limited evidence of community-based interventions for rural Latinos resulted in inclusion of urban Latino population in the literature review. However, urban and rural populations experience unique environmental and social challenges, resulting in themes from the literature that are non-specific for rural populations. Data collection from the pilot intervention reflects a small sample size of group meetings and findings from this sample does not imply generalizability in larger, alternative rural Latino 
populations. The pilot study was conducted in a specific setting of North Florida with unique environmental, social, and psychological factors. Ongoing meetings will further establish psychosocial determinants and coping strategies of mental health in rural Latinos.

\section{Conclusion}

Rural Latinos experience additional barriers to adequate and culturally competent mental health care in their communities, with limited resources resulting in significant health disparities. Community-based interventions integrate existing resources and community members to address psychosocial determinants of mental health in these vulnerable populations. This study contributes to the limited body of knowledge on rural Latino mental health interventions to work toward culturally appropriate, feasible mental health care. Further research is indicated to better understand the psychosocial components impacting mental well-being in rural Latinos both nationally and globally. Additionally, long-term studies are necessary to understand future implications of community mental health interventions and larger study sizes to address diverse Latino subcultures.

\section{References}

Alegria, M., Polo, A., Gao, S., Santana, L., Rothstein, D., Jimenez, A., . . Normand, S. L. (2008). Evaluation of a patient activation and empowerment intervention in mental health care. Med Care, 46(3), 247-256. doi:10.1097/MLR.0b013e318158af52

Baernholdt, M., Yan, G., Hinton, I., Rose, K., \& Mattos, M. (2012). Quality of Life in Rural and Urban Adults 65 Years and Older: Findings From the National Health and Nutrition Examination Survey. J Rural Health, 28(4), 339-347. http://doi.org/10.1111/j.1748-0361.2011.00403.x

Barrio, C., \& Yamada, A. M. (2010). Culturally Based Intervention Development: The Case of Latino Families Dealing With Schizophrenia. Res Soc Work Pract, 20(5), 483-492. doi:10.1177/1049731510361613

Brennan, R. L. K., Baker, E. A., \& Metzler, M. (2008). Promoting health equity: A resource to help communities address social determinants of health. Atlanta, GA: Centers for Disease Control and Prevention.

Chong, J., \& Moreno, F. (2012). Feasibility and acceptability of clinic-based telepsychiatry for lowincome Hispanic primary care patients. Telemed J E Health, 18(4), 297-304. doi:10.1089/tmj.2011.0126

Collado, A., Castillo, S. D., Maero, F., Lejuez, C. W., \& Macpherson, L. (2014). Pilot of the brief behavioral activation treatment for depression in latinos with limited english proficiency: preliminary evaluation of efficacy and acceptability. Behav Ther, 45(1), 102-115. doi:10.1016/j.beth.2013.10.001

CSDH. F. R. o. t. C. o. S. D. o. Health. Closing the gap in a generation: health equity through action on the social determinants of health. Geneva: World Health Organization; 2008. 
Cristancho, S., Peters, K. E., \& Garces, D. M. (2016). Comunidades de la Latinos y Latinas, salud mental y necesidades de servicio en las zonas rurales los EE.UU. Interam J Psychol, 50(1), 149-160.

Dwight-Johnson, M., Aisenberg, E., Golinelli, D., Hong, S., O'Brien, M., \& Ludman, E. (2011). Telephone-based cognitive-behavioral therapy for Latino patients living in rural areas: a randomized pilot study. Psychiatr Serv, 62(8), 936-942. doi:10.1176/ps.62.8.pss6208_0936

Green, M. A., Perez, G., Ornelas, I. J., Tran, A. N., Blumenthal, C., Lyn, M., \& Corbie-Smith, G. (2012). Amigas Latinas Motivando el ALMA (ALMA): Development and Pilot Implementation of a Stress Reduction Promotora Intervention. Calif J Health Promot, 10, 52-64.

HealthyPeople.gov (no date). Healthy People 2020. Washington, DC: U.S. Department of Health and Human Services, Office of Disease Prevention and Health Promotion.

Hiott, A. E., Grzywacz, J., Davis, S., Quandt, S., \& Arcury, T. (2008). Migrant farmworker stress: Mental health implications. J Rural Health, 24(1), 32-39. doi: 1748-0361.2008.00134.x

Institute of Medicine . Unequal treatment: Confronting racial and ethnic disparities in healthcare. National Academies Press; Washington, DC: 2003.

Kaltman, S., Pauk, J., \& Alter, C. L. (2011). Meeting the Mental Health Needs of Low-Income Immigrants in Primary Care: A Community Adaptation of an Evidence-Based Model. Am J Orthopsychiatry, 81(4), 543-551. doi:10.1111/j.1939-0025.2011.01125.x

Kanter, J. W., Santiago-Rivera, A. L., Rusch, L. C., Busch, A. M., \& West, P. (2010). Initial outcomes of a culturally adapted behavioral activation for Latinas diagnosed with depression at a community clinic. Behav Modif, 34(2), 120-144. doi:10.1177/0145445509359682

Kelly, U. A., \& Pich, K. (2014). Community-based PTSD treatment for ethnically diverse women who experienced intimate partner violence: a feasibility study. Issues Ment Health Nurs, 35(12), 906913. doi:10.3109/01612840.2014.931496

Lichter, D. T. (2012). Immigration and the New Racial Diversity in Rural America. Rural Sociology, 77(1), 3-35. http://doi.org/10.1111/j.1549-0831.2012.00070.x

Michael, Y. L., Farquhar, S. A., Wiggins, N., \& Green, M. K. (2008). Findings from a community-based participatory prevention research intervention designed to increase social capital in Latino and African American communities. J Immigr Minor Health, 10(3), 281-289. doi:10.1007/s10903007-9078-2

Ryan GW, Bernard RH. Techniques to identify themes. Field Methods. 2003; 15(85):85-109. DOI: $10.1177 / 1525822 \times 02239569$

Ryan, J. G., Buford, U., Arias, E., Alfonsin-Vittoria, I., Fedders, M., Jennings, T., \& Grubb, W. (2014). Participation in and impact of a depression care management program targeting low-income minority patients in an urban community-based clinic. Clin Ther, 36(5), 778-790. doi:10.1016/j.clinthera.2014.03.007

Stacciarini, J., Smith, R., Garvan, C. W., Weins, B., \& Cottler, L. B. (2014). Rural Latinos' Mental Wellbeing: A Mixed-methods Pilot study of Family, Environment and Social Isolation Factors. Community Mental Health J. doi:10.1007/s10597-014-9774-z

Stacciarini, J. R., Vacca, R., Wiens, B., Loe, E., Laflam, M., Pérez, A., \& Locke, B. (2016). FBO Leaders' Perceptions of the Psycho-social Contexts for Rural Latinos. Issues Ment Health Nurs,37(1), 19-25. doi:10.3109/01612840.2015.1076914 
Tondora, J., O'Connell, M., Miller, R., Dinzeo, T., Bellamy, C., Andres-Hyman, R., \& Davidson, L. (2010). A clinical trial of peer-based culturally responsive person-centered care for psychosis for African Americans and Latinos. Clin Trials, 7(4), 368-379. doi:10.1177/1740774510369847

Uebelacker, L. A., Marootian, B. A., Tigue, P., Haggarty, R., Primack, J. M., \& Miller, I. W. (2011). Telephone depression care management for Latino Medicaid health plan members: a pilot randomized controlled trial. J Nerv Ment Dis, 199(9), 678-683. doi:10.1097/NMD.0b013e318229d100

United States Department of Health and Human Services . Mental Health: Culture, race, and ethnicity: A supplement to mental health: A report of the Surgeon General. US Department of Health and Human Services, Substance Abuse and Mental Health Services Administration, Center for Mental Health Services; Rockville, MD: 2001.

Wells, K. B., Jones, L., Chung, B., Dixon, E. L., Tang, L., Gilmore, J., . . Miranda, J. (2013). Community-partnered cluster-randomized comparative effectiveness trial of community engagement and planning or resources for services to address depression disparities. $J$ Gen Intern Med, 28(10), 1268-1278. doi:10.1007/s11606-013-2484-3

World Health Organization \& Calouste Gulbenkain Foundation. (2014). Social determinants of mental health. World Health Organization, Geneva. 